\title{
Sea Level Variations in the Western Mediterranean Studied by a Numerical Tidal Model of the Strait of Gibraltar
}

\author{
Peter Brandt,* Angelo Rubino, ${ }^{+}$Dmitry V. Sein, \# Burkard BascheK, @ Alfredo Izquierdo, \& And \\ JAN O. BACKHAUS** \\ *Institut für Meereskunde an der Universität Kiel, Kiel, Germany \\ ${ }^{+}$Dipartimento di Scienze Ambientali dell 'Università Ca' Foscari di Venezia, Venice, Italy \\ \#Max-Planck-Institut für Meteorologie, Hamburg, Germany \\ ${ }^{\circledR}$ Institute of Ocean Sciences, Sidney, British Columbia, Canada \\ \&Universidad de Cadiz, Departamento de Fisica Aplicada, Cadiz, Spain \\ **Institut für Meereskunde, Universität Hamburg, Hamburg, Germany
}

(Manuscript received 31 January 2003, in final form 15 August 2003)

\begin{abstract}
Aspects of the sea level changes in the western Mediterranean Sea are investigated using a numerical tidal model of the Strait of Gibraltar. As a prerequisite, the performance of this model, that is, a two-dimensional, nonlinear, two-layer, boundary-fitted coordinate numerical model based on the hydrostatic approximation on an $f$ plane, is assessed in the simulation of mean and tidal circulation of the Strait of Gibraltar. The model is forced by imposing mean interface and surface displacements as well as $M_{2}, S_{2}, O_{1}$, and $K_{1}$ tidal components along the Atlantic and Mediterranean model open boundaries. Model results are compared with observations and with results obtained from a tidal inverse model for the eastern entrance of the Strait of Gibraltar. In general, good agreement is found. A sensitivity study performed by varying different model parameters shows that the model behaves reasonably well in the simulation of the averaged circulation. The model is then used to investigate the climatological sensitivity of the simulated dynamics in the Strait of Gibraltar to changes in the density difference between Atlantic and Mediterranean waters. For this purpose, given a certain density difference between Atlantic and Mediterranean waters, the authors iteratively searched for that sea level drop between the Atlantic and the Mediterranean that fulfills the mass balance of the Mediterranean. It is found that an increase of the density difference leads to an increase of the exchange flow and to an increase of the sea level drop between the two basins. A trend in the sea level drop of $O\left(1 \mathrm{~cm} \mathrm{yr}^{-1}\right)$, such as the one observed between 1994 and 1997, is explained by the model as the result of a trend of $O\left(10^{-4} \mathrm{yr}^{-1}\right)$ in the relative density difference between the Mediterranean and Atlantic waters. The observed north-south asymmetry in this trend is also captured by the model, and it is found to arise from changes in the along-strait velocity. Results suggest that the dynamics within the Strait of Gibraltar cannot be neglected when sea level changes in the western Mediterranean basin are investigated.
\end{abstract}

\section{Introduction}

Through the Strait of Gibraltar Atlantic Ocean water flows, in the near-surface layer, toward the Mediterranean Sea basin. There, this water is transformed into saltier water, which eventually leaves the Mediterranean through the same strait in the near bottom layer. Changes in the water mass characteristics in the Atlantic and/or Mediterranean waters flowing through the Strait of Gibraltar, that may result from different variations in the two neighboring basins, may profoundly affect the exchange flow through the Strait of Gibraltar (Myers and Haines 2002), which contributes to observed sea level

Corresponding author address: Peter Brandt, Institut für Meereskunde an der Universität Kiel, Düsternbrooker Weg 20, 24105 Kiel, Germany.

E-mail: pbrandt@ifm.uni-kiel.de variations in the Mediterranean Sea (Ross et al. 2000). This has been partly attributed to variations in the hydraulic regime occurring in the Strait of Gibraltar, which may flip between maximal and submaximal exchange on time scales from seasonal to interannual (Bormanns et al. 1986; Garrett et al. 1990a,b). According to the "classic" hydraulic models for the exchange flow through the Strait of Gibraltar (Bryden and Stommel 1984; Farmer and Armi 1986; Bryden and Kinder 1991) maximal exchange flow is achieved when the flow is hydraulically controlled at Camarinal Sill and Tarifa Narrows, while submaximal exchange flow is achieved when it is hydraulically controlled only at Camarinal Sill. In these theories, bathymetric cross-strait variations as well as Coriolis force are neglected. Note, however, that different fundamental aspects related to strait dynamics in a rotating flow were investigated, for example, 
by Whitehead et al. (1974), Gill (1977), Killworth and MacDonald (1993), and Whitehead and Salzig (2002). In a recent study, Helfrich and Pratt (2003) were able to establish different relations between hydraulically controlled sill flow and circulation in a finite upstream basin using a two-dimensional reduced-gravity model. More realistic numerical models allow one to consider both cross-strait bathymetric variations and Coriolis force. In this case a more complex picture of the exchange flow through the Strait of Gibraltar emerges: it is characterized by fragmented regions where the flow is hydraulically controlled, which are interrupted by regions of subcritical flow (Izquierdo et al. 2001).

Considering the occurrence of a transition layer between Atlantic and Mediterranean waters, that is, the existence of a three-layer system, where the interface layer is an active participant in the process of exchange (Bray et al. 1995), adds further complexity to the simulated exchange flow through the Strait of Gibraltar (Sannino et al. 2002). Moreover, this exchange flow is influenced by the tides. Quasi-steady as well as nonsteady theories (mostly still based on one-dimensional equations) predict that the exchange flow increases with tidal amplitude (Farmer and Armi 1986; Helfrich 1995; Brandt et al. 1996). Thus, a profound knowledge of the two-dimensional tidal dynamics in the Strait of Gibraltar is fundamental for the prediction of variations in the exchange flow. This relevance is a reason why, in past years, different large projects have been initiated to observe extensively the temporally and spatially varying flow structure within the Strait of Gibraltar. Armi and Farmer (1988), for instance, presented experimental evidences of the existence of control points for the outflowing water at the Spartel Sill and at the Camarinal Sill and for the inflowing water at the Tarifa Narrows. During part of the observations, the control was permanent only at the Spartel Sill and at the Tarifa Narrows. According to these findings, in the frame of the hydraulic control theory, the exchange flow in the Strait of Gibraltar was thus maximal during this part of the observational period. More recently, during the Canary Islands Azores Gibraltar Observations (CANIGO) project, an attempt was made to measure the tidal flow as well as the exchange flow at different locations within the strait (García Lafuente et al. 2000; Tsimplis 2000; Tsimplis and Bryden 2000; Baschek et al. 2001; Send and Baschek 2001; Morozov et al. 2002; García Lafuente et al. 2002; Send et al. 2002). Parallel, increasingly complex numerical models addressed similar aspects (e.g., see Wang 1993; Brandt et al. 1996; Tejedor et al. 1999; Izquierdo et al. 2001; Sannino et al. 2002).

Now, not only the existence of different theories, but also the large dataset available allows for an accurate assessment of the performance of numerical models; that is, we can obtain characteristics of the simulated tidal flow as well as exchange flow in the Strait of Gibraltar that are consistent with the underlying dataset and with the existing theories. Once this result is achieved, these numerical models can be used to investigate the climatological sensitivity of the simulated dynamics in the Strait of Gibraltar. This is the goal of our investigation. For this purpose, first we compare results of a high-resolution hydrodynamic numerical model (Izquierdo et al. 2001) with results of the inverse tidal model (Baschek et al. 2001) as well as with different bottom pressure and tide gauge measurements (García Lafuente 1986; Candela et al. 1990) and we assess the model robustness against different theories. Then, on this basis, we study the simulated variations in the strength of the exchange flow as well as in the sea level drop between Atlantic and Mediterranean due to variations of the density difference between Atlantic and Mediterranean water. The paper is organized as follows: In section 2 the models are described. The validation of the hydrodynamical numerical model is presented in section 3 . In section 4 the simulated timeaveraged exchange flow is described and the sensitivity of the model to different parameters, including the climatological relevant density difference between Atlantic and Mediterranean waters, is presented. Last, in section 5 the results of the present study are discussed.

\section{The models}

\section{a. Tidal inverse model}

The tidal inverse model used in our investigation is described in detail in Baschek et al. (2001). This model represents a fit to data taken during extensive measurements at the eastern entrance of the Strait of Gibraltar (Ceuta-Algeciras section) in the frame of CANIGO. Shipboard measurements with vessel-mounted and lowered ADCPs were complemented with moored current meters over a period of $4.5 \mathrm{yr}$. These data were sorted into a grid of 16 horizontal and 29 vertical boxes and averaged to 2 -h intervals.

The observed two-dimensional flow field at the eastern entrance of the strait was fitted by simple analytical functions corresponding to the seven most important tidal components as well as the time-averaged flow. In this way the model was able to explain $92 \%$ of the variance of the lower layer flow but significantly less in the upper 150-200 m, where currents due to, for example, propagating internal bores and the nonlinear interaction of subinertial barotropic flows associated with low-frequency atmospheric pressure disturbances on both sides of the strait with the tidal flow (Mañanes et al. 1998) may be important.

\section{b. Hydrodynamic numerical model}

The model used for this investigation is the two-dimensional, nonlinear, two-layer numerical model described by Izquierdo et al. (2001) extended to include the eastern part of the Gulf of Cadiz and the western part of the Alboran Sea. In this domain, the model equa- 


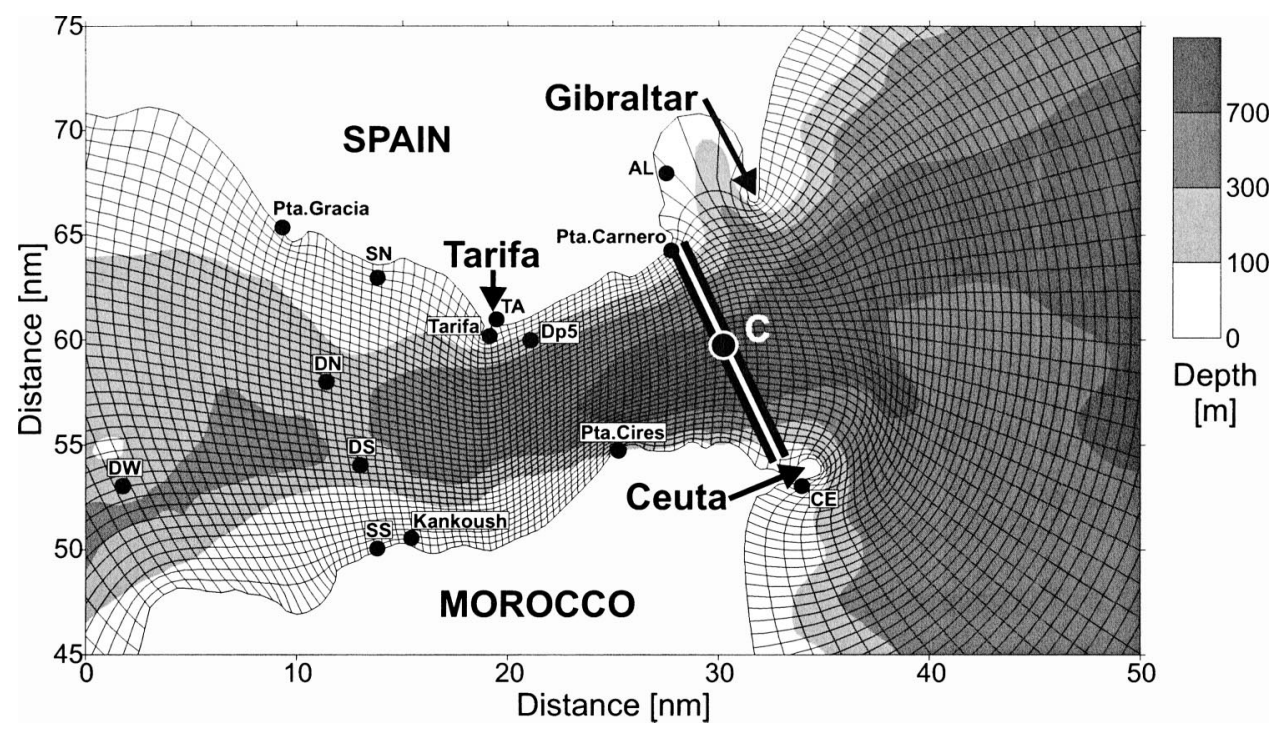

FIG. 1. Grid map as well as bottom topography used in the numerical model. Also shown is the section at the eastern entrance of the Strait of Gibraltar to which the inverse model refers, the position of mooring $\mathrm{C}$, and locations of bottom pressure and tide gauge measurements.

tions were integrated employing boundary-fitted coordinates. The curvilinear grid used has a cell size of about $1 \mathrm{~km}$ at the Atlantic and Mediterranean boundaries, which decreases toward the center of the strait where it is about $0.125 \mathrm{~km}$ (Fig. 1). The bathymetry was deduced from the ETOPO5 database and complemented, where required, by data from the comprehensive chart published by Instituto Geográfico Nacional y SECEG (1988). The values of the density in the upper and lower layer, $\rho_{1}$ and $\rho_{2}$, were specified as 1027 and $1029 \mathrm{~kg}$ $\mathrm{m}^{-3}$, respectively. The values chosen for quadratic interface friction, quadratic bottom friction, and harmonic horizontal eddy viscosity coefficients were $0.001,0.01$, and $63.9 \mathrm{~m}^{2} \mathrm{~s}^{-1}$, respectively. This set of parameters (which yields good agreement with observations as we show in the next section) defines the central experiment of our investigation, to which we refer in the next section as well as in section 4, where different sensitivity experiments will be carried out. The model was run initially without tides, using a first guess for the mean interface depth and surface elevation. Radiation conditions for the sea surface as well as for the interface depths were implemented along the two open boundaries. This allowed for an adjustment of the sea surface and interface depth until an almost stationary state was reached. On this basis, the model was forced at the open boundaries with prescribed surface elevation amplitudes and phases of the $M_{2}, S_{2}, K_{1}$, and $O_{1}$ tidal constituents as obtained from the numerical tidal model of Tsimplis et al. (1995). Note that, at the open boundaries, this tidal forcing was superimposed on the obtained surface elevations, which were considered as fixed there. Radiation conditions were thus maintained only for treatment of the interface depths.
The model was run in all experiments for 30 semidiurnal tidal cycles to achieve a stable periodic solution. After this solution was reached, the model run was extended for another 228 days, simulating the period from 15 September 1997 to 1 May 1998, to which the calculations performed with the tidal inverse model refer. Thus all tidal constituents were set according to this time. For further details about the model equations and configuration the reader is referred to the work of Izquierdo et al. (2001).

\section{Validation of the hydrodynamical numerical model}

Here the results obtained in our central experiment are compared with data from the current-meter moorings deployed at the eastern entrance of the Strait of Gibraltar during CANIGO and with the inverse model of Baschek et al. (2001) described above as well as with sea surface elevations observed in different locations within the strait (see Fig. 1).

A qualitative comparison of different time series of the along-strait velocity as obtained from our numerical model, from observations, and from the inverse model for two different depths at location $\mathrm{C}$ marked in Fig. 1 is shown in Fig. 2. The two current meters of this mooring were deployed at 45- and 210-m water depth (see also Fig. 3), measuring for a period of nearly 5 months. Note that, according to the results of the inverse model, the upper instrument was located in the upper layer and the lower instruments in the lower layer. For this comparison, the inverse model was applied to obtain currents at the nominal depth of the moored current meters, while the numerical model only provides one value for the 

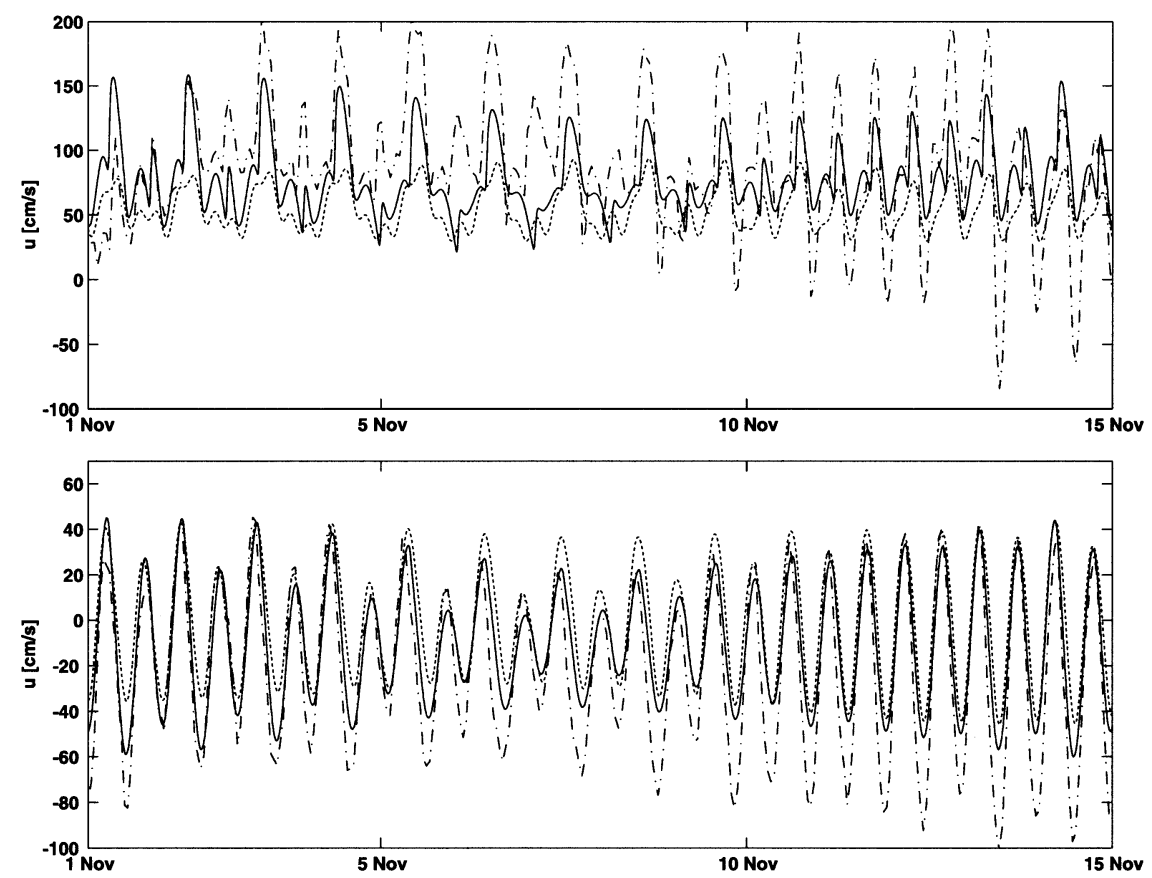

FIG. 2. Along-strait velocity time series at the eastern entrance of the Strait of Gibraltar (location $\mathrm{C}$ of Fig. 1) as obtained from the numerical model (solid lines), observations (dashed-dotted lines), and the inverse model (dashed lines). The instruments were deployed at depths of (upper) 45 and (lower) $210 \mathrm{~m}$. The velocity simulated by the numerical model refers to the upper layer in the top panel and to the lower layer in the bottom panel.
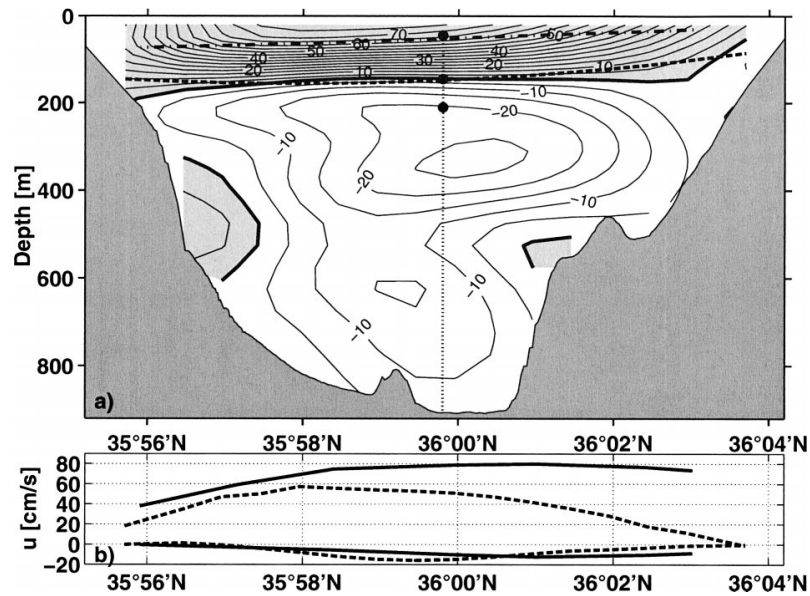

FIG. 3. Time-averaged velocities and interface depths from inverse and numerical models at the eastern entrance of the Strait of Gibraltar (see Fig. 1). (a) Contours show the time-averaged velocities from the inverse model; the dashed line and the dashed-dotted line show the time-averaged interface depth from the inverse model (see text for definition) and from the numerical model. (b) The upper- and lowerlayer mean velocities from the inverse model (dashed lines) and numerical model (solid lines) are depicted. Note that the values from the inverse model are calculated by vertically integrating over the corresponding layer thickness. upper- and lower-layer flow, respectively. All given values refer to along-strait currents having a $20^{\circ}$ angle relative to east.

Comparison between the time series in the upper layer shows that, in general, the observed amplitudes are larger than the simulated ones, while their shape is quite similar. The strong observed negative peaks can be explained by the subduction of the current meters into the lower layer (where the currents are more negative) because of large vertical movements of the current meters. In the lower layer the agreement is much better, although here also the observed amplitudes are larger than the simulated ones. The time series produced by the inverse model show, in both layers, smaller amplitudes than the corresponding observed and simulated ones. The fact that the inverse tidal model does not take into account the whole tidal spectrum is particularly evident in the current spectra of the two current time series (Fig. 4). The numerical model does simulate all major peaks present in the observed data, even though the simulated spectral densities are generally lower at higher frequencies. Especially the agreement at the first two peaks (semidiurnal and diurnal tide) is very good. Here, also the inverse model yields good results, although it cannot explain the higher-frequency peaks.

In Fig. 3 a comparison between the results obtained using the inverse model and simulated by the numerical model is depicted. We note that the mean currents in 

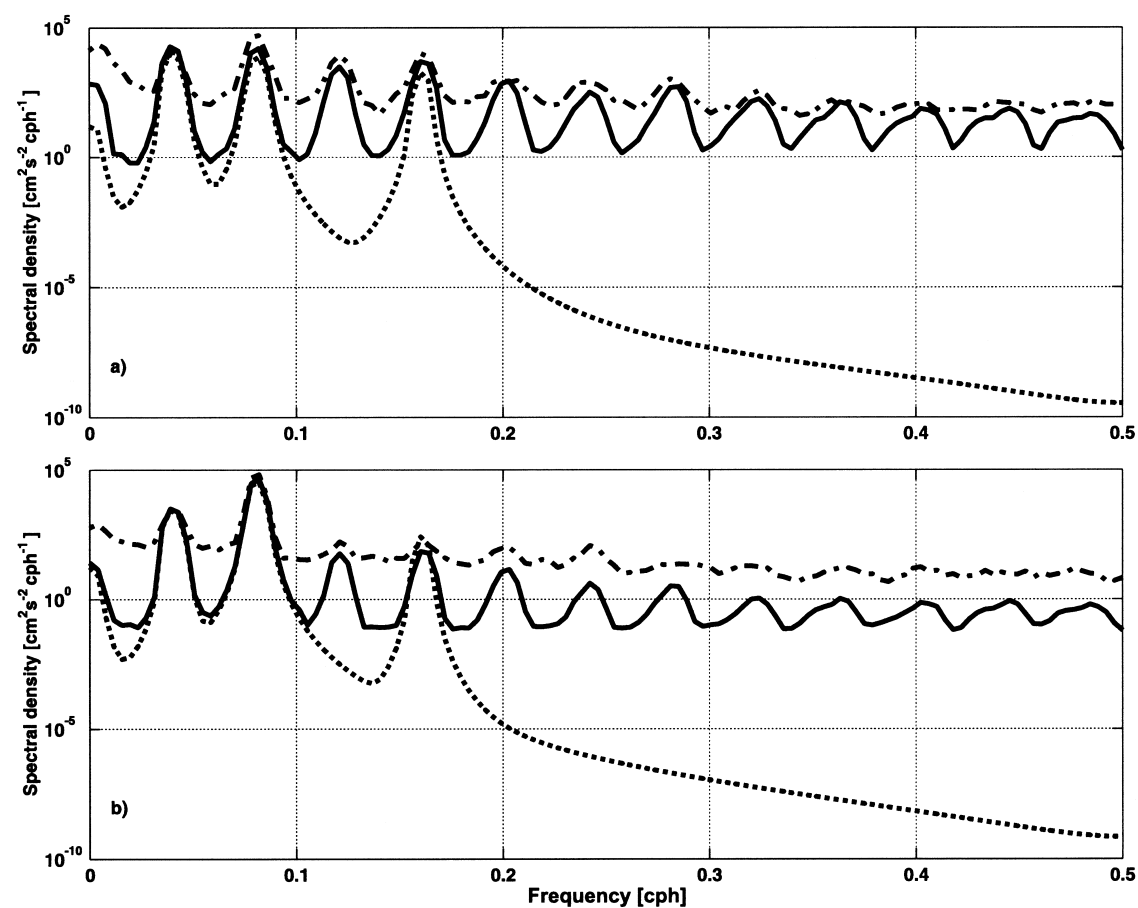

FIG. 4. Spectra of the along-strait velocity at the eastern entrance of the Strait of Gibraltar (see Fig. 1) as obtained from the numerical model (solid lines), observations (dashed-dotted lines), and the inverse model (dashed lines). The instruments were deployed at depths of (a) 45 and (b) $210 \mathrm{~m}$. The velocity of the numerical model refers to the upper layer in (a) and the lower layer in (b).

the upper layer are always larger than those produced by the inverse model, while the values in the lower layer are quite similar (Fig. 3b). A much better agreement in the upper layer arises when comparing the maximum velocity values, which are both about $80 \mathrm{~cm} \mathrm{~s}^{-1}$. Note that, particularly within the upper layer, a strong vertical gradient in the velocity field exists at the eastern entrance of the Strait of Gibraltar, which of course cannot be resolved with our two-layer model. The time-averaged volume transport at the eastern entrance as obtained by the numerical model yields $0.62 \mathrm{~Sv}(\mathrm{~Sv} \equiv$ $10^{6} \mathrm{~m}^{3} \mathrm{~s}^{-1}$ ) for the upper layer and $-0.59 \mathrm{~Sv}$ for the lower layer, while the volume transport of the inverse model is $0.81 \pm 0.07$ and $-0.7 \pm 0.07 \mathrm{~Sv}$, respectively; that is, this comparison shows only small differences. Note that the simulated interface between Atlantic and Mediterranean waters is significantly shallower than the observed one (Fig. 3a). This is related to the fact that mixing processes are neglected in our numerical model. Bray et al. (1995) show, in fact, experimental evidence of a transition layer between Mediterranean and Atlantic waters at the eastern entrance of the Strait of Gibraltar with maximum thickness of about $110 \mathrm{~m}$, which cannot be simulated by our numerical model. However, the simulated interface position farther west, in the region between Camarinal Sill and Tarifa Narrows (Fig. 5b), where the thickness of the observed transition layer reaches a minimum, is much closer to observed values. In the inverse model, this interface (defined as the isohaline for which the transports in both layers are maximum) corresponds to the 38.1 isohaline at the eastern entrance (Baschek et al. 2001) while it lies between the 37.4 and 38 isohaline near Camarinal Sill (Tsimplis and Bryden 2000). In the numerical model, instead, the density is constant within each layer, resulting in a constant density step between the two layers throughout the strait.

A general indication of the model behavior regarding the simulated surface tides can be evinced from Table 1 , where simulated and observed surface elevation amplitudes and phases of the $M_{2}$ tide at different locations (see Fig. 1) are presented. In general, good agreement is achieved, especially in the phase of the tide. Note, however, that the simulated amplitudes are significantly smaller than the observed ones. Better agreement between simulated and observed amplitudes was obtained by, for example, Tejedor et al. (1999) who, however, used a barotropic model of much smaller spatial extension forced at the open boundaries with observed surface elevations.

The results of the comparison carried out between the hydrodynamical numerical model and the inverse model as well as observations allow us to use the numerical model for investigating the sensitivity of the simulated dynamics in the Strait of Gibraltar to changes in model 
a)

\section{Surface position [m]}

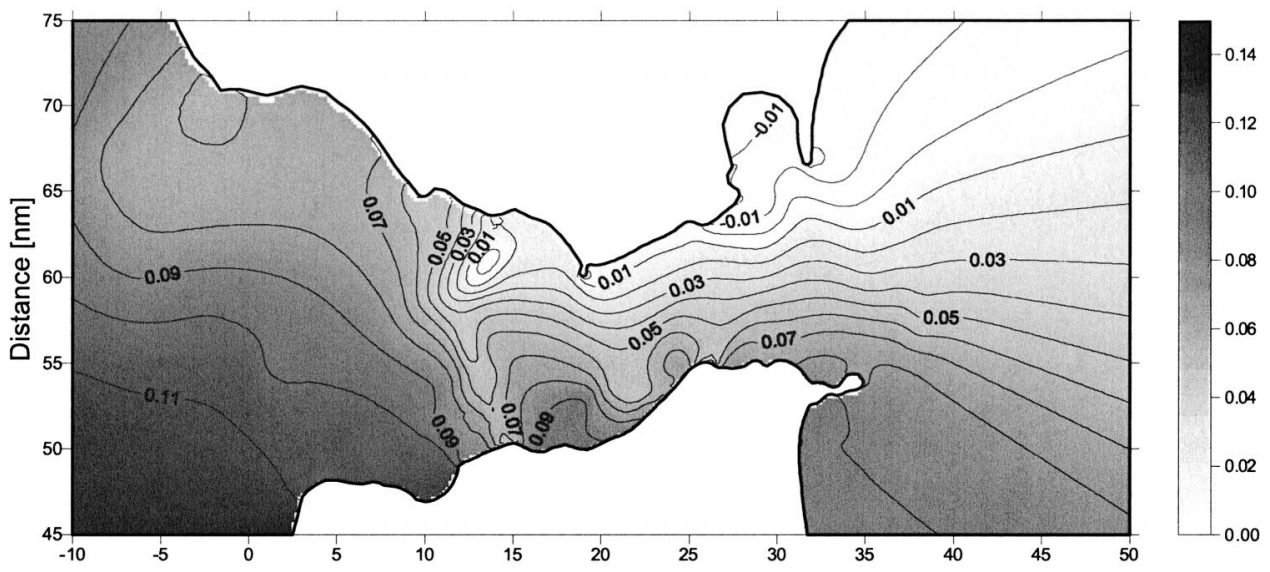

b)

Interface position [m]

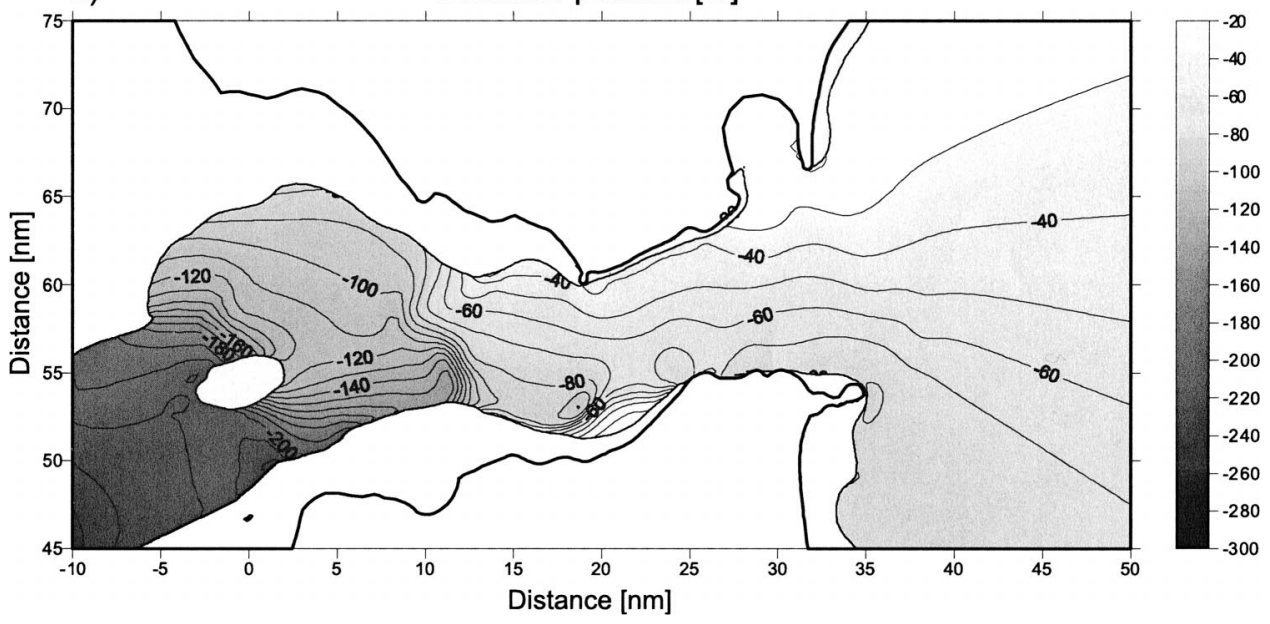

FIG. 5. Time-averaged (a) sea surface and (b) interface positions as simulated by our numerical model for the model parameters that define our central experiment.

TABLE 1. Amplitude and phase of the $M_{2}$ tidal component as observed and simulated at different locations within the Strait of Gibraltar (see Fig. 1). Data are obtained from García Lafuente (1986) and Candela et al. (1990).

\begin{tabular}{lccccc}
\hline \hline & \multicolumn{2}{c}{ Observed } & & \multicolumn{2}{c}{ Numerical model } \\
\cline { 2 - 3 } \cline { 5 - 6 } & $\begin{array}{c}\text { Amplitude } \\
(\mathrm{cm})\end{array}$ & $\begin{array}{c}\text { Phase } \\
\left({ }^{\circ}\right)\end{array}$ & & $\begin{array}{c}\text { Ampli- } \\
\text { tude }(\mathrm{cm})\end{array}$ & $\begin{array}{c}\text { Phase } \\
\left({ }^{\circ}\right)\end{array}$ \\
\hline Punta Gracia & $64.9 \pm 0.2$ & $49 \pm 0.5$ & & 57.8 & 48.2 \\
DN & 60.1 & 51.8 & & 48.1 & 51.0 \\
DS & 54.0 & 61.8 & & 45.3 & 61.2 \\
SN & 52.3 & 47.6 & & 43.4 & 43.1 \\
SS & 57.1 & 66.8 & & 51.1 & 67.0 \\
DW & 78.5 & 56.1 & & 67.6 & 58.3 \\
Kankoush & $51.8 \pm 0.4$ & $69 \pm 0.5$ & & 40.8 & 64.0 \\
Tarifa & $41.5 \pm 0.2$ & $57 \pm 0.5$ & & 38.1 & 38.4 \\
TA & 41.2 & 41.2 & & 36.9 & 40.9 \\
Dp5 & 44.4 & 47.6 & & 35.2 & 40.1 \\
Punta Cires & $36.4 \pm 0.2$ & $46.5 \pm 0.5$ & & 27.7 & 53.4 \\
AL & 31.0 & 48.0 & & 27.5 & 43.0 \\
Punta Carnero & $31.1 \pm 0.2$ & $47.5 \pm 0.5$ & & 26.2 & 38.2 \\
CE & 29.7 & 50.3 & & 25.0 & 52.6 \\
\hline
\end{tabular}

parameters like friction, horizontal viscosity, and tidal amplitude, and in the climatologically relevant density difference.

\section{The exchange flow in the Strait of Gibraltar \\ a. The time-averaged exchange flow}

On the basis of the model validation carried out in the previous section we will now present in detail aspects of the time-averaged exchange flow in the Strait of Gibraltar as simulated by our numerical model for the model parameters that define our central experiment (see section 2). In Fig. 5 the mean surface and interface positions are depicted, which illustrate the mean alongstrait and cross-strait pressure gradients in a central region of our model domain. The model yields a mean along-strait sea level difference of about $6 \mathrm{~cm}$ between the two opposite entrances of the strait. The sea level decrease toward east is, however, irregular, which can 
a) Upper layer along-strait velocity $[\mathrm{m} / \mathrm{s}]$

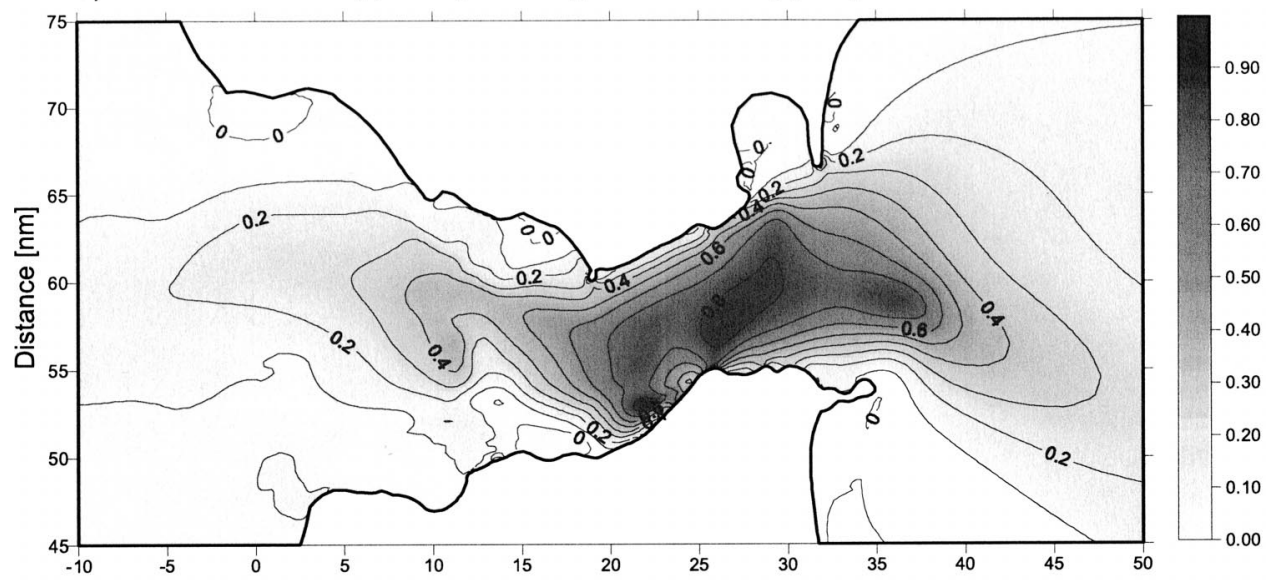

b) Lower layer along-strait velocity $[\mathrm{m} / \mathrm{s}]$

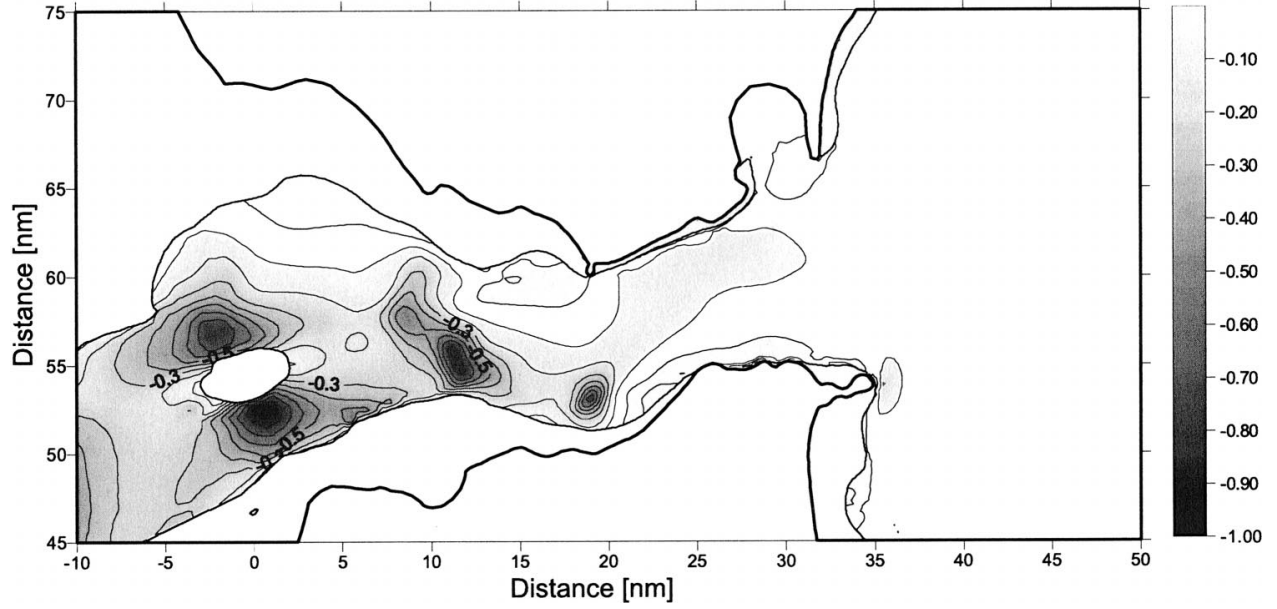

FIG. 6. Time-averaged (a) upper-layer and (b) lower-layer along-strait velocity as simulated by our numerical model for the model parameters that define our central experiment.

be, at least partly, explained as due to the upper-layer flow over a variable lower-layer interface. Especially in the sill region this effect is evident: a band of decreased sea level crossing the strait can be found over Camarinal Sill where the interface strongly slopes down toward west. Across the strait, a sea level difference of about $3 \mathrm{~cm}$ at the western entrance and of about $9 \mathrm{~cm}$ at the eastern entrance is simulated, which accounts for the noticeable importance of the Coriolis force in the presence of a variable upper-layer thickness and hence velocities. A similar, but opposite, structure is found for the interface depth: a weak cross-strait gradient at the eastern entrance and a strong one at the western entrance are encountered there.

The time-averaged upper- and lower-layer along-strait velocities (i.e., along the along-strait coordinate of our model; see Fig. 1) are depicted in Fig. 6. In the upper layer, large velocities (up to $0.8 \mathrm{~m} \mathrm{~s}^{-1}$ ) are found in the eastern part of the strait while, in the lower layer, there are several regions where values up to $-0.7 \mathrm{~m} \mathrm{~s}^{-1}$ are encountered. These regions are located near Camarinal and Spartel Sills and, together with Tarifa Narrows, correspond to regions where the flow is hydraulically controlled (Fig. 7). To identify these regions, a composite Froude number defined as $G=G_{1}+G_{2}$ was calculated, with

$$
G_{1,2}=\left\langle\frac{u_{1,2}^{2}}{g \Delta \rho / \rho H_{1,2}}\right\rangle,
$$

where $u_{1,2}$ are the upper- and lower-layer velocities, $H_{1,2}$ are the upper- and lower-layer thicknesses, $g$ is the acceleration of gravity, $\Delta \rho$ is the density difference between both layers, and $\rho$ is the mean density. The angle brackets denote a time average over the whole simulation period. The model simulates, on average, a control of the outflow at the Spartel Sill and a control of the inflow at the Camarinal Sill while, at the Tarifa Narrows, only within an isolated region near the northern shore the inflow is hydraulically controlled. This, in the frame 
of hydraulic theory, would correspond, on average, to maximal exchange flow through the Strait of Gibraltar. Note that a detailed discussion about the temporal variability of these control regimes within a tropical month can be found in Izquierdo et al. (2001).

\section{b. Model sensitivity to variations of tidal amplitudes, friction, and eddy viscosity coefficients}

In Table 2 the time-averaged transports of Atlantic and Mediterranean waters, their differences, and their sums from our central experiment as well as from seven experiments, in which we varied tidal amplitudes and coefficients of interface and bottom friction as well as horizontal eddy viscosity, are presented.

The difference between Atlantic and Mediterranean water transports represents the exchange flow through the Strait of Gibraltar. First, we look at the exchange flow variations induced by variations of the imposed tidal amplitudes. For this purpose we reduced/enhanced the amplitudes of all considered tidal components by $30 \%$ without any changes in their phases. As predicted by one-dimensional theories (Farmer and Armi 1986; Helfrich 1995; Brandt et al. 1996) the exchange flow increases for increasing tidal amplitudes. By quantitatively comparing our results with previous results, we note a reduced sensitivity of the simulated changes on this parameter. In fact, our $\pm 30 \%$ variation in tidal amplitude results only in an about $\pm 3 \%$ change in the obtained time-averaged transport. Note that the same variation would result in an about $\pm 22 \%$ change in accordance to the quasi-steady theory (Farmer and Armi $1986)$ and in an about $\pm 15 \%$ change in accordance with the results of Helfrich (1995), which would be slightly reduced (about $\pm 13 \%$ ) when including bottom and interface friction (Brandt et al. 1996). While it is beyond the scope of this investigation to establish a quantitative evaluation of the sensitivity of the simulated exchange flow on tidal amplitude, we note that, for example, realistic bathymetry, Coriolis force, and realistic tides are included in our numerical model, but they are neglected in the theories quoted above.

Second, we study the sensitivity of the simulated exchange flow to variations in the quadratic friction parameters. To this purpose we reduced/enhanced always both interfacial and bottom friction parameter together, the bottom friction parameter always being one order of magnitude larger than the interfacial one. We note that the model is very sensitive to changes in these parameters (see Table 2). Not surprising, an increased friction leads to a decreased exchange flow.

Third, we investigate the role played by the eddy viscosity coefficient in determining the simulated exchange flow. In the model we used a harmonic eddy viscosity with constant coefficient. Our results indicate that the simulated exchange flow is virtually insensitive to variations in the eddy viscosity coefficient, at least in the explored parameter range.
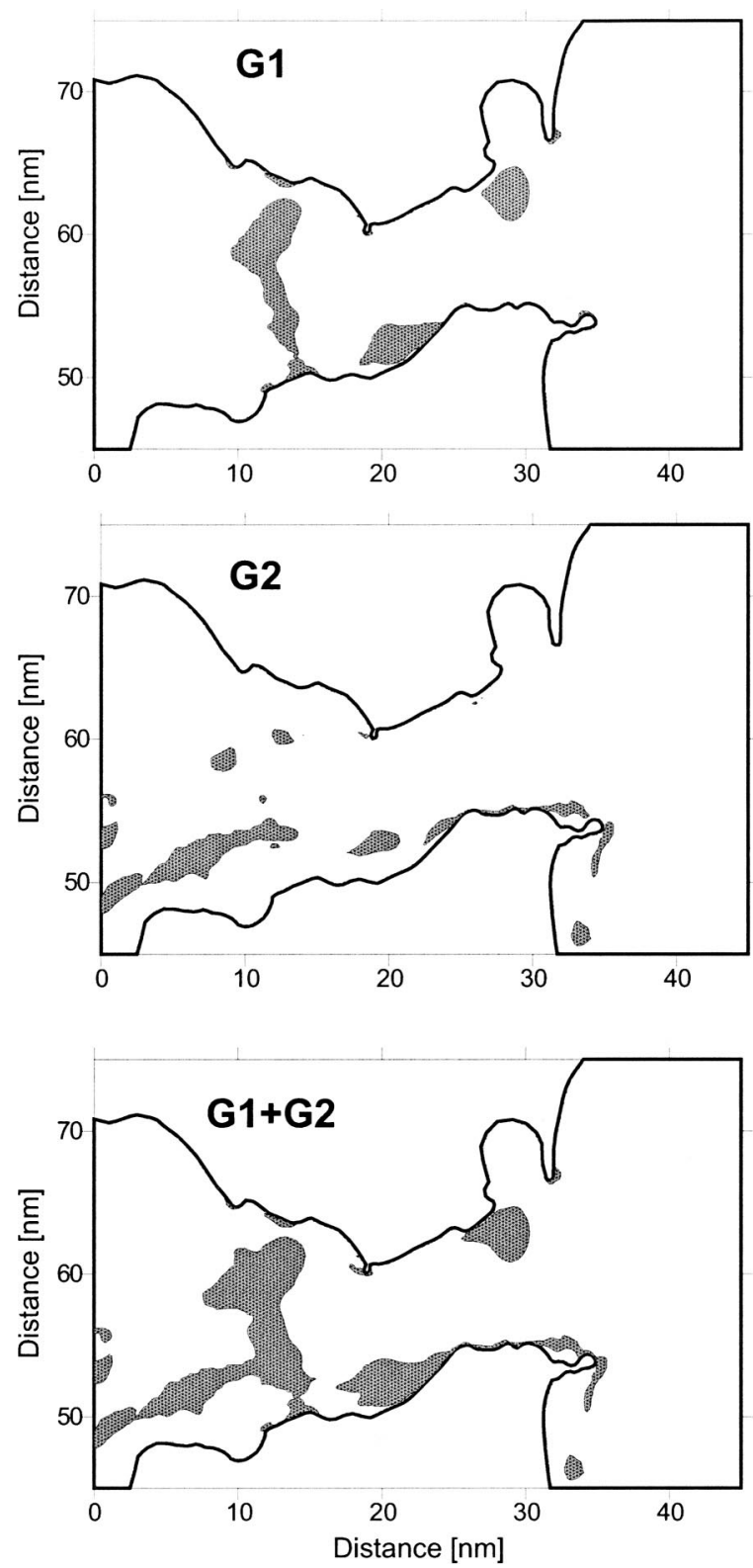

FIG. 7. Geographic maps of the Strait of Gibraltar with inserted regions where the time-averaged upper layer (G1), lower layer (G2), and composite Froude number $(\mathrm{G} 1+\mathrm{G} 2)$ as simulated by our numerical model for the model parameters that define our central experiment are larger than 1 (gray-shaded patches).

The sum of Atlantic and Mediterranean water transport represents the net transport through the Strait of Gibraltar. A deviation of this value from the value needed to balance the water lost in the Mediterranean by evaporation minus precipitation and river runoff would imply changing mean sea level in this basin. This adjustment would result also in an adjustment in the alongstrait pressure gradient to establish again a mass balance in the Mediterranean. Our model, however, does not yield a temporal evolution in the sea level drop between 
TABLE 2. Time-averaged transport values obtained from different model simulations by varying the given parameters as compared with the central experiment. Here, $c_{\text {int }}$ is the quadratic interface friction coefficient, $c_{\text {bot }}$ is the quadratic bottom friction coefficient, $A_{H}$ is the harmonic eddy viscosity coefficient, and $\Delta \rho / \rho$ is the relative density difference.

\begin{tabular}{|c|c|c|c|c|}
\hline & \multicolumn{2}{|c|}{ Transport of } & \multirow[b]{2}{*}{$\begin{array}{l}\text { Difference of both } \\
\text { transports }(\mathrm{Sv})\end{array}$} & \multirow[b]{2}{*}{$\begin{array}{l}\text { Sum of both } \\
\text { transports }(\mathrm{Sv})\end{array}$} \\
\hline & $\begin{array}{c}\text { Atlantic } \\
\text { water }(\mathrm{Sv})\end{array}$ & $\begin{array}{c}\text { Mediterranean } \\
\text { water }(\mathrm{Sv})\end{array}$ & & \\
\hline \multicolumn{5}{|c|}{ Central expt $\left(c_{\text {int }}=0.001, c_{\text {bot }}=0.01, A_{H}=63.9 \mathrm{~m}^{2} \mathrm{~s}^{-1}\right.}$, \\
\hline Increased tidal amplitude $(+30 \%)$ & 0.656 & -0.605 & 1.261 & 0.051 \\
\hline Decreased tidal amplitude $(-30 \%)$ & 0.590 & -0.602 & 1.192 & -0.012 \\
\hline Increased friction $\left(c_{\mathrm{int}}=0.0013, c_{\mathrm{bot}}=0.013\right)$ & 0.578 & -0.549 & 1.127 & 0.029 \\
\hline Decreased friction $\left(c_{\text {int }}=0.0007, c_{\text {bot }}=0.007\right)$ & 0.674 & -0.647 & 1.321 & 0.027 \\
\hline Tiny friction $\left(c_{\mathrm{int}}=0.0004, c_{\mathrm{bot}}=0.004\right)$ & 0.733 & -0.723 & 1.456 & 0.010 \\
\hline Increased viscosity $\left(A_{H}=191.7 \mathrm{~m}^{2} \mathrm{~s}^{-1}\right)$ & 0.665 & -0.548 & 1.213 & 0.117 \\
\hline Decreased viscosity $\left(A_{H}=21.3 \mathrm{~m}^{2} \mathrm{~s}^{-1}\right)$ & 0.597 & -0.607 & 1.204 & -0.010 \\
\hline Increased density difference $(\Delta \rho / \rho=0.0021)$ & 0.602 & -0.647 & 1.249 & -0.045 \\
\hline Decreased density difference $(\Delta \rho / \rho=0.0019)$ & 0.641 & -0.540 & 1.181 & 0.101 \\
\hline
\end{tabular}

the two basins because it encompasses only a limited region in the approaches to the Strait of Gibraltar, at whose boundaries the mean sea surface elevation is fixed. The net transport shows in general a smaller sensitivity within the studied parameter range than the exchange flow. Here, we only mention the response of the net transport to a variation in the values of the friction coefficients (see Table 2): an increased friction leads to a slightly enhanced net transport because it reduces the Mediterranean outflow more than the Atlantic inflow.

\section{c. Climatological scenarios: Sensitivity to density variations}

We investigate now the sensitivity of the simulated exchange flow to changes in the (climatologically relevant) density difference between Atlantic and Mediterranean waters. The results of our investigation show that an increase in the density difference (i.e., an increase in the baroclinic pressure gradient and hence in the Mediterranean outflow) yields an increase in the simulated exchange flow and a decrease in the net inflow (see Table 2). Consider now a climatic variation, in which the density difference between Atlantic and Mediterranean waters is changed but which does not affect the mass balance within the Mediterranean. In this case the change in the density difference must be connected with a change in the along-strait pressure gradient and hence in the sea level drop from the Atlantic to the Mediterranean in order to keep the net inflow constant. On the other hand, an abrupt change in the density difference between the two waters would result in a variation of the net inflow. As a consequence the sea level in the Mediterranean must change and eventually a new equilibrium is reached in which the mass balance is fulfilled again.

In our numerical model, given a certain density difference between Atlantic and Mediterranean waters, we can iteratively search for the sea level drop that yields the same net inflow as in our central experiment. To reach this goal, the iterations were performed by adding a constant offset to the fixed sea level at the Mediterranean boundary. We found that, in the case of an increased/decreased relative density difference (relative to our central experiment) of $10^{-4}$, an increase/decrease of $0.73 \mathrm{~cm}$ in the sea level drop between Atlantic and Mediterranean yields the same net inflow as in our central experiment. Note that, in the different iteration runs for a given density difference, the exchange flow (i.e., the difference between Atlantic and Mediterranean transport) remains virtually constant (see Table 2) and that, for the considered range of density differences, we found no change in the hydraulic regime: all of these simulations yield almost the same spatial distribution of control regions as depicted in Fig. 7.

\section{Discussion}

In past years, especially because of the advent of satellite altimetry, large sea level changes in the Mediterranean have been observed (Cazenave et al. 2001). The recognition of the causes responsible for such changes is, however, complicated by the fact that the Mediterranean is not an isolated basin (Ross et al. 2000). Together with changes in the interior of the Mediterranean, like, for example, the warming trend in intermediate and deep water observed in the eastern basin since the early 1990s and in the western basin since the 1960s (Bethoux et al. 1990, 1998; Cazenave et al. 2001), changes in sea level of the Atlantic and in the exchange flow through the Strait of Gibraltar may be, in fact, important. Among the latter, changes of the hydraulic regime from submaximal to maximal and of the connected mixing strength have been proposed (Ross et al. 2000; Myers and Haines 2002). In the present work, we have focused our attention on the effect that changes in density difference between Atlantic and Mediterranean waters will have on the sea level drop between the two basins. To investigate such effect we used a high-resolution, two-dimensional, nonlinear, two-layer bound- 


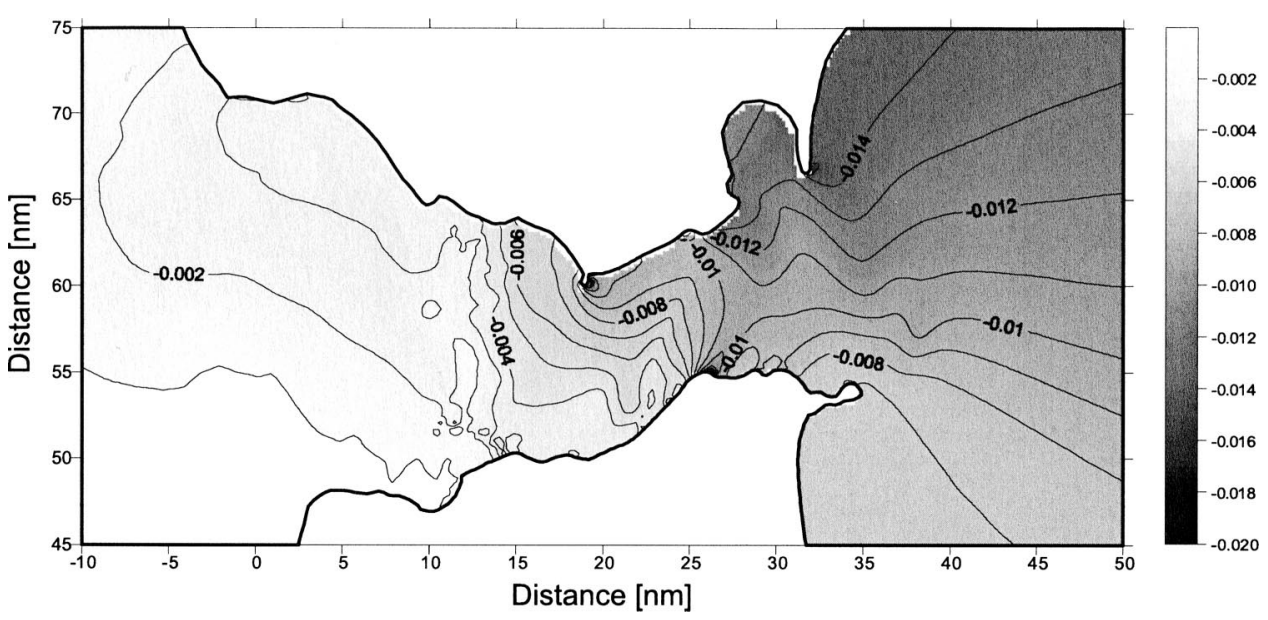

FIG. 8. Difference in the surface position between the two model runs assuming relative density differences between Atlantic and Mediterranean waters of 0.0021 and 0.0019 , as well as a constant offset of the mean sea level at the Mediterranean boundary of -0.73 and $+0.73 \mathrm{~cm}$, respectively.

ary-fitted coordinate tidal model (Izquierdo et al. 2001): we calculated, iteratively, the sea level drop needed, given a certain density difference, to ensure the mass balance within the Mediterranean. A trend in the sea level drop $O\left(1 \mathrm{~cm} \mathrm{yr}^{-1}\right)$, such as the one observed between 1994 and 1997 (Ross et al. 2000), is explained by our model as the result of a trend in the relative density difference between the Mediterranean and Atlantic waters $O\left(10^{-4} \mathrm{yr}^{-1}\right)$. Note that, for the range of relative density differences considered, we found no change in the hydraulic regime: all of these simulations yield almost the same spatial distribution of control regions as depicted in Fig. 7. Our numerical model allows one also to infer, for the scenario of a changing density difference, the two-dimensional structure of the sea level variation. In Fig. 8 the difference in the mean sea surface elevation between the model runs carried out assuming relative density differences of 0.0021 and 0.0019 as well as a constant offset of the mean sea level at the Mediterranean boundary of -0.73 and $+0.73 \mathrm{~cm}$, respectively, is depicted. While, as expected, the sea surface elevation in the Atlantic approaches to the Strait of Gibraltar does not differ noticeably in the two experiments, the opposite is true in the Mediterranean approaches to the Strait of Gibraltar. There, both mean sea level elevations and its north-south gradient differ between the experiments. We note that the change in the sea level drop is larger at the northern shore than at the southern shore, in agreement with the observations reported by Ross et al. (2000). The reason for this behavior is the change in the exchange flow through the Strait of Gibraltar between both experiments. The stronger exchange flow in the run with a stronger density difference leads to a stronger along-strait velocity and, because of the effect of the Coriolis force, to a stronger north-south gradient in the surface elevation. Note, however, that a change in the exchange flow through the Strait of Gibraltar implies a change in the salt bal- ance within the Mediterranean and thus a change in the water mass salinity. A warming of the Mediterranean outflow, for instance, would lead to a decrease in the sea level drop between the two basins but also to an increase of the salinity in the Mediterranean. The system would probably adjust to a new equilibrium, whose prediction would involve a realistic model of the whole Mediterranean.

Acknowledgments. We thank J. García Lafuente (University of Malaga, Spain) for the contribution of the current-meter data of mooring $\mathrm{C}$ (CANIGO). This work has been partly supported by Project GEMA REN 20001168-CO2-02 MAR.

\section{REFERENCES}

Armi, L., and D. M. Farmer, 1988: The flow of Mediterranean water through the Strait of Gibraltar. Progress in Oceanography, Vol. 21, Pergamon, 1-105.

Baschek, B., U. Send, J. García Lafuente, and J. Candela, 2001: Transport estimates in the Strait of Gibraltar with a tidal inverse model. J. Geophys. Res., 106, 31 033-31 044.

Bethoux, J. P., B. Gentili, J. Raunet, and D. Tailliez, 1990: Warming trend in the western Mediterrenean deep water. Nature, 347, 660-662.

,-- , and D. Tailliez, 1998: Warming and freshwater budget change in the Mediterranean since the 1940s, their possible relation to the greenhouse effect. Geophys. Res. Lett., 25, 1023 1026.

Bormans, M., C. Garrett, and K. Thompson, 1986: Seasonal variability of the surface inflow through the Strait of Gibraltar. Oceanol. Acta, 9, 403-414.

Brandt, P., W. Alpers, and J. O. Backhaus, 1996: Study of the generation and propagation of internal waves in the Strait of Gibraltar using a numerical model and synthetic aperture radar images of the European ERS 1 satellite. J. Geophys. Res., 101, $14237-14252$.

Bray, N. A., J. Ochoa, and T. H. Kinder, 1995: The role of the interface in exchange through the Strait of Gibraltar. J. Geophys. Res. 100, $10755-10776$.

Bryden, H. L., and H. M. Stommel, 1984: Limiting processes that 
determine basic features of the circulation in the Mediterranean Sea. Oceanol. Acta, 7, 289-296.

— , and T. H. Kinder, 1991: Recent progress in strait dynamics Rev. Geophys., 29, 617-631.

Candela, J., C. Winant, and A. Ruiz, 1990: Tides in the Strait of Gibraltar. J. Geophys. Res., 95, 7313-7335.

Cazenave, A., C. Cabanes, K. Dominh, and S. Mangiarotti, 2001: Recent sea level change in the Mediterranean Sea revealed by TOPEX/Poseidon satellite altimetry. Geophys. Res. Lett., 28, 1607-1610.

Farmer, D. M., and L. Armi, 1986: Maximal two-layer exchange over a sill and through the combination of a sill and contraction with barotropic flow. J. Fluid Mech., 64, 53-76.

García Lafuente, J., 1986: Variabilidad del nivel del mar en el Estrecho de Gibraltar: Mareas y oscilaciones residuales. Ph.D. thesis, Instituto Español de Oceanografía, Fuengirola, Málaga, Spain, $154 \mathrm{pp}$

_ J. M. Vargas, F. Plaza, T. Sarhan, J. Candela, and B. Baschek, 2000: The tide at the eastern section of the Strait of Gibraltar. J. Geophys. Res., 105, 14 197-14 213.

_, J. Delgado, J. M. Vargas, M. Vargas, F. Plaza, and T. Sarhan, 2002: Low-frequency variability of the exchange flows through the Strait of Gibraltar during CANIGO. Deep-Sea Res., 49B, 4051-4067.

Garrett, C., M. Bormans, and K. Thompson, 1990a: Is the exchange through the Strait of Gibraltar maximal or submaximal? The Physical Oceanography of Sea Straits, L. J. Pratt, Ed., Kluwer Academic, 271-294.

- K. Thompson, and W. Blanchard, 1990b: Sea-level flips. Nature, 348, 292

Gill, A. E., 1977: The hydraulics of rotating channel flow. J. Fluid Mech., 80, 641-71.

Helfrich, K. R., 1995: Time-dependent two-layer hydraulic exchange flows. J. Phys. Oceanogr., 25, 359-373.

- and L. J. Pratt, 2003: Rotating hydraulics and upstream basin circulation. J. Phys. Oceanogr., 33, 1651-1663.

Instituto Geográfico Nacional y SECEG, 1988: Mapa Fisico. Madrid, Spain.

Izquierdo, A., L. Tejedor, D. V. Sein, J. O. Backhaus, P. Brandt, A. Rubino, and B. A. Kagan, 2001: Control variability and internal bore evolution in the Strait of Gibraltar: A 2D two-layer model study. Estuarine Coastal Shelf Sci., 53, 637-651.

Killworth, P. D., and N.-R. MacDonald, 1993: Maximal reduced- gravity flux in rotating hydraulics. Geophys. Astrophys. Fluid Dyn., 70, 31-40.

Mañanes, R., M. Bruno, J. Alonso, B. Fraguela, and L. Tejedor, 1998: Non-linear interaction between tidal and subinertial barotropic flows in the Strait of Gibraltar. Oceanol. Acta, 2, 33-46.

Morozov, E. G., K. Trulsen, M. G. Velarde, and V. I. Vlasenko, 2002: Internal tides in the Strait of Gibraltar. Deep-Sea Res., 49B, 3193-3206.

Myers, P. G., and K. Haines, 2002: Stability of the Mediterranean's thermohaline circulation under modified surface evaporative fluxes. J. Geophys. Res., 107, 3021, doi:10.1029/2000JC000550.

Ross, T., C. Garrett, and P.-Y. Le Traon, 2000: Western Mediterranean sea-level rise: Changing exchange flow through the Strait of Gibraltar. Geophys. Res. Lett., 27, 2949-2952.

Sannino, G., A. Bargagli, and V. Artale, 2002: Numerical modeling of the mean exchange through the Strait of Gibraltar. J. Geophys. Res., 107, 3094, doi:10.1029/2001JC000929.

Send, U., and B. Baschek, 2001: Intensive shipboard observations of the flow through the Strait of Gibraltar. J. Geophys. Res., 106, $31017-31032$

_ - P. F. Worcester, B. D. Cornuelle, C. O. Tiemann, and B. Baschek, 2002: Integral measurements of mass transport and heat content in the Strait of Gibraltar from acoustic transmissions. Deep-Sea Res., 49B, 4069-4095.

Tejedor, L., A. Izquierdo, B. A. Kagan, and D. V. Sein, 1999: Simulation of the semidiurnal tides in the Strait of Gibraltar. $J$. Geophys. Res., 104, 13 541-13 557.

Tsimplis, M. N., 2000: Vertical structure of tidal currents over the Camarinal Sill at the Strait of Gibraltar. J. Geophys. Res., 105, $19709-19728$

—- and H. L. Bryden, 2000: Estimation of the transports through the Strait of Gibraltar. Deep-Sea Res., 47A, 2219-2242.

— R. Proctor, and R. A. Flather, 1995: A two-dimensional tidal model for the Mediterranean Sea. J. Geophys. Res., 100, 16223 16239.

Wang, D.-P., 1993: The Strait of Gibraltar Model: Internal tide, diurnal inequality and fortnightly modulation. Deep-Sea Res., 40A, 1187-1203.

Whitehead, J. A., and J. Salzig, 2002: Rotating channel flow: Control and upstream currents. Geophys. Astrophys. Fluid Dyn., 95, 185226

- A. Leetmaa, and R. A. Knox, 1974: Rotating hydraulics of strait and sill flows. Geophys. Fluid Dyn., 6, 101-125. 